\title{
Influence of Cutting Speed on the Hob Wear in Hobbing with the Minimum Quantity Lubrication
}

\author{
Wojciech STACHURSKI, Bogdan KRUSZYŃSKI
}

\begin{abstract}
In the paper the influence of cutting speed on the hob wear in gear hobbing when minimum quantity lubrication (MQL) cutting fluid supply method was applied, is described. Gears made of C45 steel were cut with the use of the hobs made of HS6-5-2 high-speed steel. For comparison, some tests with flood cutting fluid supply mode were performed. The investigations were carried out for four cutting speeds with constant feed rate and the full depth of tooth spaces. The tool wear was measured in a direct way, as the width of the flank wear land $\left(V B_{c}\right.$ parameter). The results of the investigations were presented in the form of the diagrams of the distribution of tool wear on consecutive hob teeth vs. time, and also as the diagrams of the tool wear changes for the most loaded hob's tooth. By the use of the Taylor's equation the influence of the cutting speed on the hob tool life T period was determined. Based on the results obtained it was found that the MQL method can be an alternative solution for the cutting fluid supply in hobbing.
\end{abstract}

Keywords: hobbing; hob wear; MQL; tool life

\section{INTRODUCTION}

The machining with the minimum quantity lubrication (MQL) cutting fluid supply method is a developing technology domain. However, in some industrial applications, it is still a novelty. The investigations carried out by various authors, e.g. [1-3] showed that the use of the MQL method in certain cutting conditions allows obtaining cutting results comparable to the conventional cutting fluid supply, significantly better than in dry machining.

For hobbing, the available publications [4-6] show that the impact of the MQL method on the effectiveness of the hobbing process has not been investigated yet in a wide extent. During the gear hobbing the material allowance is removed by many hob teeth, each removing different volume and shape of work material. It results in uneven wear of the cutting edges [7]. Thus the experimental investigation of the effectiveness of the use of the MQL method in this particular machining method is fully justified.

In the Institute of Machine Tools and Production Engineering of Lodz University of Technology the investigations concerning the application of the minimum quantity lubrication (MQL) in hobbing are carried out [8, 9]. One of the important research problems is the determination of the influence of the cutting fluid application method on the hob wear in cutting with various cutting parameters. This is because these parameters are decisive to a great extent for the tool wear rates.

The investigations of the hobbing of gear teeth carried out over a long time, e.g. [10], proved that the cutting speed $v_{c}$ has the most important influence on the tool wear from among all the cutting parameters. This is because cutting velocity strongly influences cutting temperatures which, in turn, influences unfavourably tool wear and tool life. This has been confirmed also by other researchers, e.g. [11].

The investigations described below were aimed at the determination of the impact of the cutting speed in hobbing with the application of MQL method on the hob wear. The assessment of the effectiveness of various methods of fluid supply was performed by the measurements of the hob wear throughout the whole tool life period. The results obtained for MQL method were compared with those obtained for wet machining.

\section{TEST CONDITIONS}

The investigations were carried out on the ZFC-20 hobbing machine. In the course of the investigations, the spur gears made of $\mathrm{C} 45$ carbon steel in the normalized state ( $20 \pm 1$ HRC) were machined with a hobbing cutter NMFc3/20\%/B made of high-speed steel HS6-5-2.

In the experiments two methods of the fluid supply methods were applied: (1) flood mode (Wet MachiningWM), and (2) Minimum Quantity Lubrication (MQL) mode.

As a conventional cutting fluid for WM mode a machine cutting oil supplied to the cutting zone with the rate of $10 \mathrm{l} / \mathrm{min}$ was used. For the MQL method, the MICRO 3000 cutting fluid supplied by the manufacturer of the MicroJet MKS-G100 device manufactured by Link company was used in experiments. The MKS-G100 device is designed for external, one-duct system of oil mist generation. The cutting fluid in the MQL method was fed at the rate $50 \mathrm{ml} / \mathrm{h}$.

The investigations were carried out for four cutting speeds at constant feed rate. Full profiles of the teeth were generated in one pass. Due to the fact that depending on the applied cutting speed various time is needed to produce one gear, it was assumed that the criterial parameter for wear will be the constant hobbing length $L=400 \mathrm{~mm}$. The cutting parameters are listed in Tab. 1. The cutting parameters values were taken on the basis of the author's earlier experimental studies [8,9] and workshop practice.

\begin{tabular}{|c|c|c|}
\multicolumn{2}{|c}{ Table 1 Cutting parameters } \\
\hline $\begin{array}{c}\text { Cutting speed } \\
v_{\mathrm{c}} / \mathrm{m} / \mathrm{min}\end{array}$ & $\begin{array}{c}\text { Feed } \\
f / \mathrm{mm} / \mathrm{rev}\end{array}$ & $\begin{array}{c}\text { Cutting depth } \\
a_{\mathrm{p}} / \mathrm{mm}\end{array}$ \\
\hline 33,4 & \multirow{2}{*}{6,6} \\
\hline 44,2 & 0,5 & 6,6 \\
\hline 54,0 & & \\
\hline 69,9 & &
\end{tabular}

The wear land of the hob cutting teeth occurred on the flank faces as the uneven wear land along the cutting edges, see Fig. 1. No significant crater wear was observed on the 
teeth rakes. The highest $V B_{\mathrm{C}-\text { in }}$ wear land width was observed in the corner area at the tooth side entering the tooth space in its generation. That value was taken into account at the analysis of the investigation results.

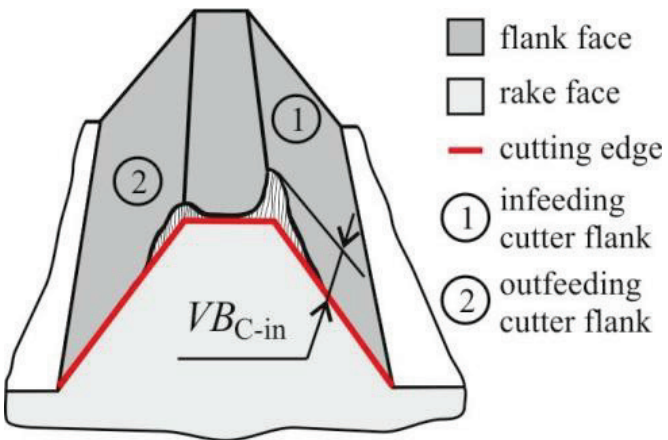

Figure 1 The distribution of the tooth flank wear land along the cutting edge

The tool wear was measured on the Carl Zeiss Jena optical microscope, equipped with a special holder for fixing the hobbing cutter in a precisely defined, repeatable position. Measurements have been started from tooth no. 1. The way of identification has been explained in Fig. 2 . It was the tooth which was the first obtained full profile of cutting edge. Next subsequent teeth had been measured along helical curve of the hob.

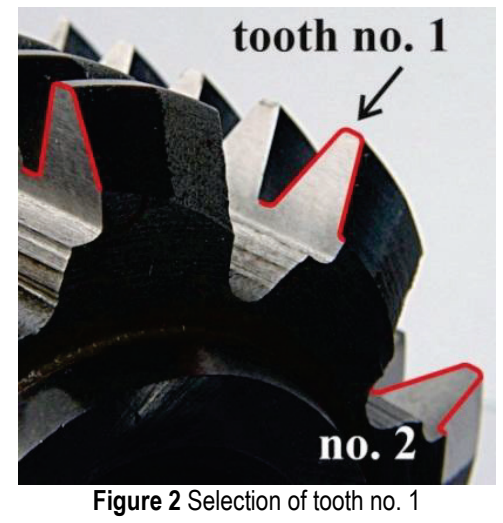

\section{INVESTIGATION RESULTS}

\subsection{Distribution of the $V B_{\mathrm{C} \text {-in }}$ Wear on the Hob Teeth}

The distribution of the $V B_{\mathrm{C}-\text { in }}$ wear land on all the hob teeth is presented in Fig. 3. The results were obtained for four machine cutting speeds: $v_{\mathrm{c}}=34,4 \mathrm{~m} / \mathrm{min}$ (Fig. $3 \mathrm{a}$ ), $v_{\mathrm{c}}$ $=44,2 \mathrm{~m} / \mathrm{min}$ (Fig. 3b), $v_{\mathrm{c}}=54 \mathrm{~m} / \mathrm{min}$ (Fig. 3c) and $v_{\mathrm{c}}=$ $69,9 \mathrm{~m} / \mathrm{min}$ (Fig. 3d). The other machine cutting parameters were constant (see Tab. 1).

Depending on the applied method of the cutting fluid supply (WM or MQL) and the cutting speed, the number of the teeth with visible wear land changes. The results of the observations are presented in Tab. 2.

Table 2 The number of the teeth with visible wear land

\begin{tabular}{|c|c|c|c|c|}
\hline & \multicolumn{5}{|c|}{ Cutting speed $v_{\mathrm{c}} / \mathrm{m} / \mathrm{min}$} \\
\hline & 33,4 & 44,2 & 54,0 & 69,9 \\
\hline & \multicolumn{5}{|c|}{ Number of teeth } \\
\hline MQL & 7 & 11 & 12 & 14 \\
\hline WM & 5 & 8 & 8 & 11 \\
\hline
\end{tabular}

For the MQL method the flank wear occurred on a larger number of teeth than when applying wet machining
(WM). This may indicate higher cutting temperatures occurring when hobbing with MQL. Better cooling and lubrication action in WM method prevent generation of higher temperatures which may deteriorate tool material properties for teeth that remove smaller volumes of work material in tooth space generation. However, it does not affect the assessment of the durability of the hob since it concerns teeth where the wear land is small. In both cases, with an increase of the cutting speed the observed wear land involves a larger number of teeth. This may be the result of the fact that with the increase of the cutting speed the cutting temperature also increases even on the cutting edges removing smaller volumes of work material.

\subsection{The Distribution of the $V B_{\mathrm{C}-\text { in }}$ Flank Wear Land for the Most Loaded Tooth of the Hob}

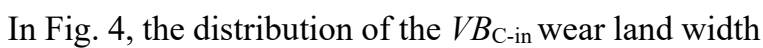
over time for the most loaded tooth of the hob is shown, in relation to the method of cutting fluid supply. The results are presented for four cutting speeds: $v_{\mathrm{c}}=34,4 \mathrm{~m} / \mathrm{min}$ (Fig. $4 \mathrm{a}), v_{\mathrm{c}}=44,2 \mathrm{~m} / \mathrm{min}$ (Fig. $\left.4 \mathrm{~b}\right), v_{\mathrm{c}}=54 \mathrm{~m} / \mathrm{min}$ (Fig. 4c), $v_{\mathrm{c}}$ $=69,9 \mathrm{~m} / \mathrm{min}$ (Fig. $4 \mathrm{~d})$. The time needed to produce one gear varied, depending on the applied cutting speed, hence the different machining times are indicated on the diagrams.

Based on the obtained results shown in Fig. 4, it can be seen that for both methods of cutting fluid supply (WM and $\mathrm{MQL})$ an increase in the $v_{\mathrm{c}}$ cutting speed causes an increase of the $V B_{\text {C-in }}$ hob wear rates. The lower wear rates for the same cutting speeds occur during hobbing with WM.

For cutting speeds from $v_{\mathrm{c}}=34,4 \mathrm{~m} / \mathrm{min}$, up to $v_{\mathrm{c}}=54$ $\mathrm{m} / \mathrm{min}$ the tool wear curves corresponding to the various methods of cutting fluid supply show similar trends, and the inclination of the curves shows that the application of the MQL method supplies sufficient lubrication at the cutting zone to ensure similar temperature levels of the process without any excessive increase in the $V B_{\mathrm{C} \text {-in wear. }}$ Higher values of wear land widths obtained for MQL are caused by poor cooling action in comparison with WM. Nevertheless, differences are not high which makes it possible to apply successfully MQL method in this range of cutting velocities.

For higher cutting speeds, especially for $v_{\mathrm{c}}=69,9$ $\mathrm{m} / \mathrm{min}$, the difference in the inclination of the wear curve corresponding to the MQL method is much higher if compared to the curve corresponding to the wet machining. It should be pointed out that the cutting speed about 70 $\mathrm{m} / \mathrm{min}$ is outside the cutting speeds applied usually for high speed steels. That inclination is steeper proving that the wear rate for hobbing with MQL is substantially higher. This may indicate, most probably, a high thermal load of the tool cutting edges when applying the MQL method due to poor cooling as well as worse access of lubricant for high cutting velocities. It should be noted that during the investigated hobbing time no evidence can be observed of the third period of rapid tool wear increase leading to the catastrophic destruction of the tool.

The results obtained showed that cutting velocities about $45-50 \mathrm{~m} / \mathrm{min}$ are the threshold values for successful MQL method application in hobbing conditions investigated. 
a)
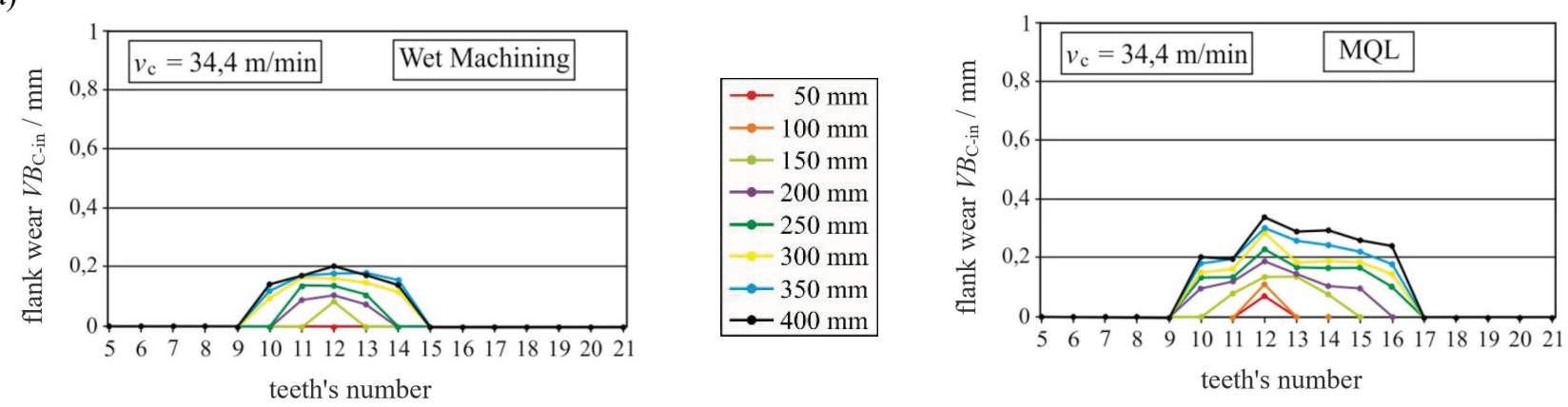

b)
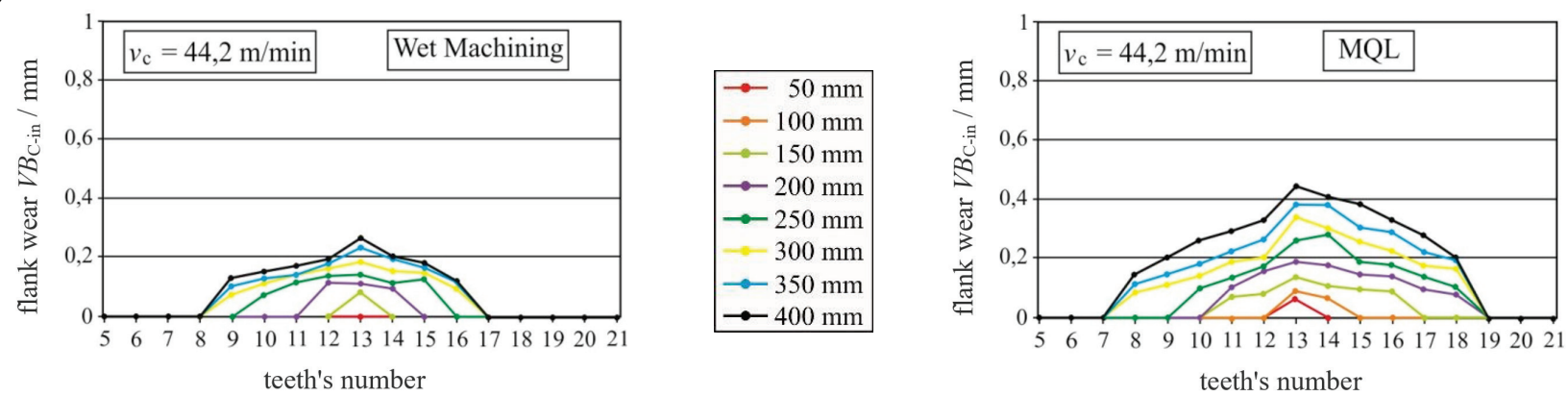

c)
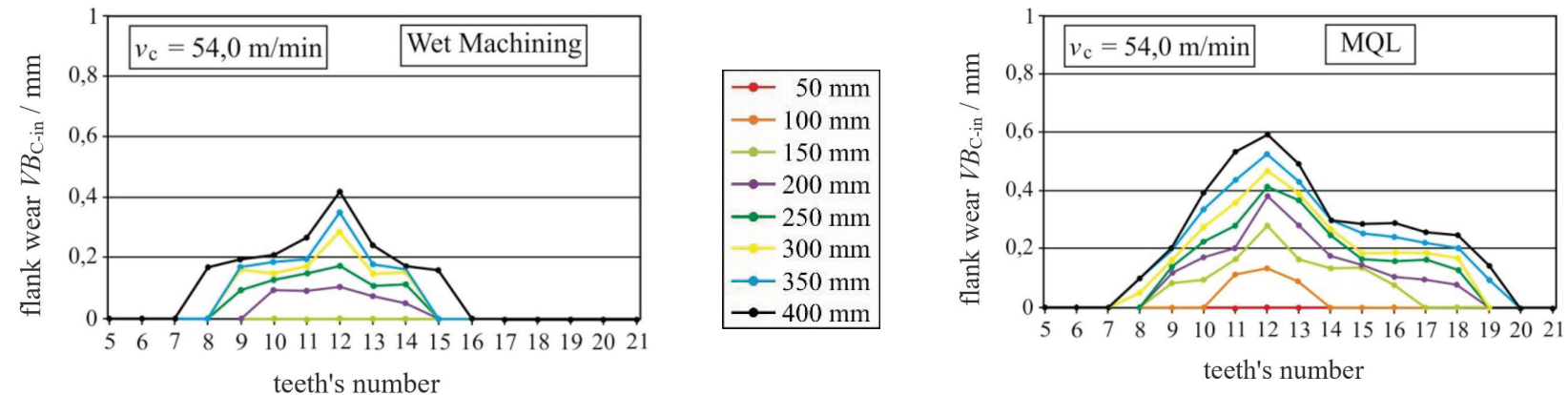

d)
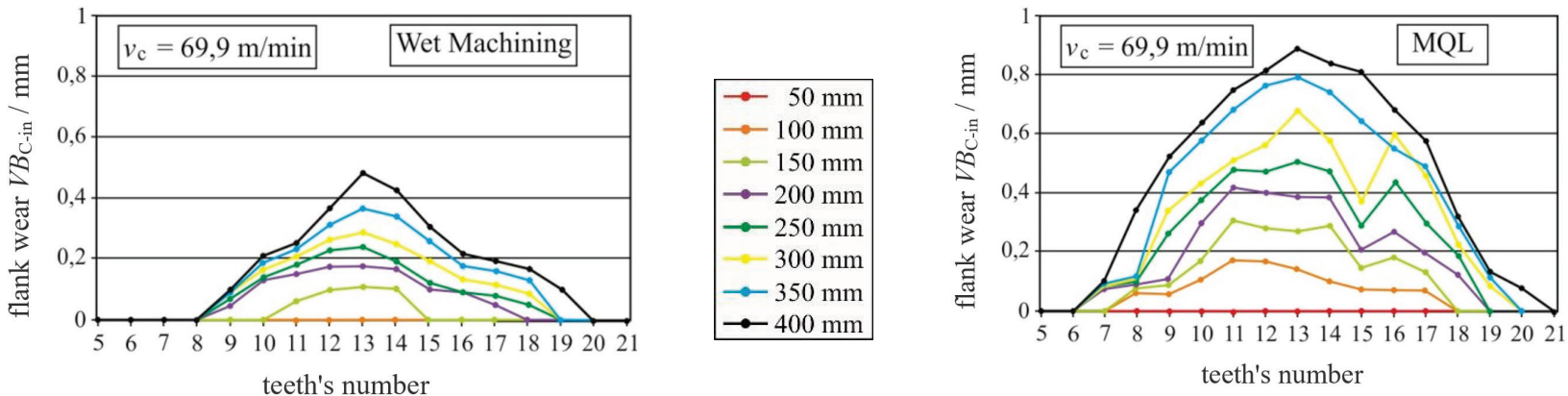

Figure 3 The distribution of the $V B_{\mathrm{C} \text {-in }}$ flank wear land width on the successive teeth of the hob over time, for the two methods of fluid supply modes: a) $v_{\mathrm{c}}=34,4 \mathrm{~m} / \mathrm{min}$, b) $v_{\mathrm{c}}=44,2 \mathrm{~m} / \mathrm{min}$, c) $\left.v_{\mathrm{c}}=54 \mathrm{~m} / \mathrm{min}, \mathrm{d}\right) v_{\mathrm{c}}=69,9 \mathrm{~m} / \mathrm{min}$

In Fig. 5 the comparison of the values of the maximal $V B_{\text {C-in }}$ hob wear land width after 104 minutes of machining for both investigated methods of cutting fluid supply is presented. Investigations were carried out for four machine cutting speeds at the constant hobbing time $t_{\mathrm{g}}=104 \mathrm{~min}$. For the cutting speed $v_{\mathrm{c}}=34,4 \mathrm{~m} / \mathrm{min}$ the hobbing travel was $L=200 \mathrm{~mm}$, for $v_{\mathrm{c}}=44,2 \mathrm{~m} / \mathrm{min}$ it was $260 \mathrm{~mm}$, for $v_{\mathrm{c}}=54 \mathrm{~m} / \mathrm{min}$ it was $325 \mathrm{~mm}$, and for $v_{\mathrm{c}}=69,9 \mathrm{~m} / \mathrm{min}$ it was $400 \mathrm{~mm}$. Other cutting parameters were constant.

The analysis of the diagram presented in Fig. 5 shows that an increase of the cutting speed brings about a change in the differences between the $V B_{\mathrm{C} \text {-in }}$ magnitudes within the same ranges of cutting speeds. When comparing the tool wear corresponding to wet machining and that with minimum quantity lubrication it was observed that for $v_{\mathrm{c}}=$ $34,4 \mathrm{~m} / \mathrm{min}$ the difference between them amounts to $75 \%$, for $v_{\mathrm{c}}=44,2 \mathrm{~m} / \mathrm{min}-69 \%$, and for $v_{\mathrm{c}}=54 \mathrm{~m} / \mathrm{min}$ it reaches $69 \%$. This indicates that good lubrication is provided in the cutting zone in the lower range of cutting speeds investigated. Such a disproportionate increase in the wear rate compared to other cutting speeds may indicate the substantial differences in the process temperature levels. Hence, the conclusion for high cutting speeds (at the HSS application limits or higher) is that the MQL method does not provide conditions to apply MQL with results 
comparable to WM, due to the higher temperature levels poorer lubrication and cooling.
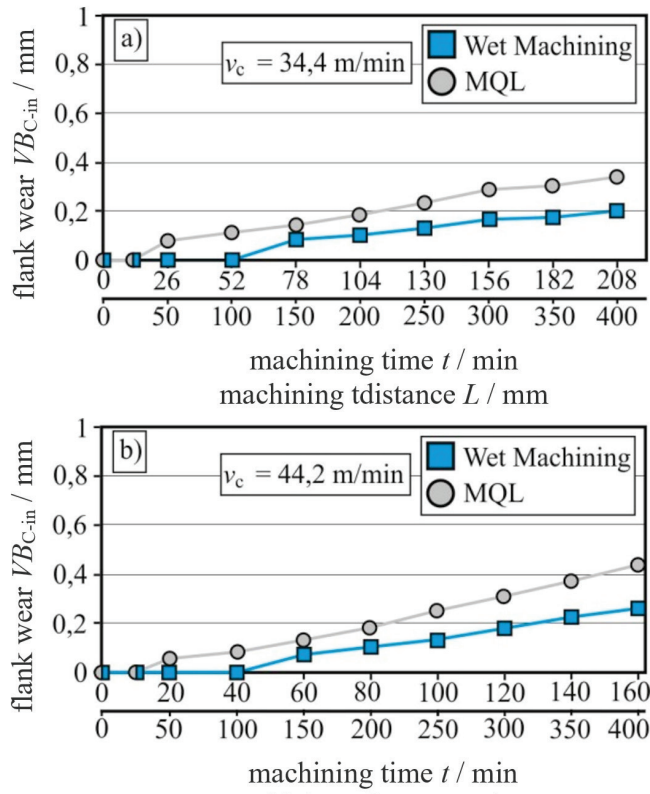

machining tdistance $L / \mathrm{mm}$
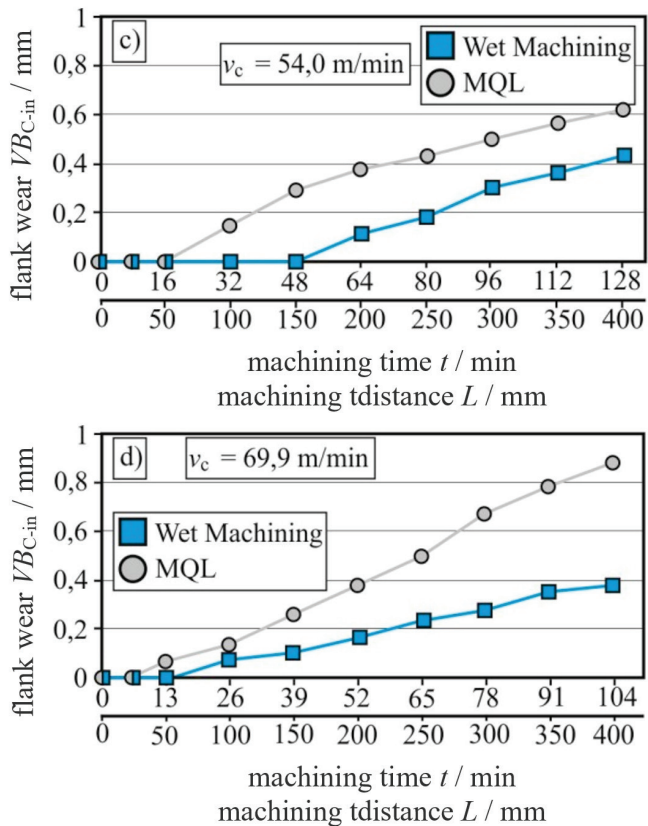

Figure 4 Changes of maximum $V B_{\mathrm{C} \text {-in }}$ wear land width over hobbing time for the two different methods of cutting fluid supply: a) $v_{\mathrm{c}}=34,4 \mathrm{~m} / \mathrm{min}$, b) $v_{\mathrm{c}}=44,2$ $\left.\mathrm{m} / \mathrm{min}, \mathrm{c}) v_{\mathrm{c}}=54 \mathrm{~m} / \mathrm{min}, \mathrm{d}\right) v_{\mathrm{c}}=69,9 \mathrm{~m} / \mathrm{min}$

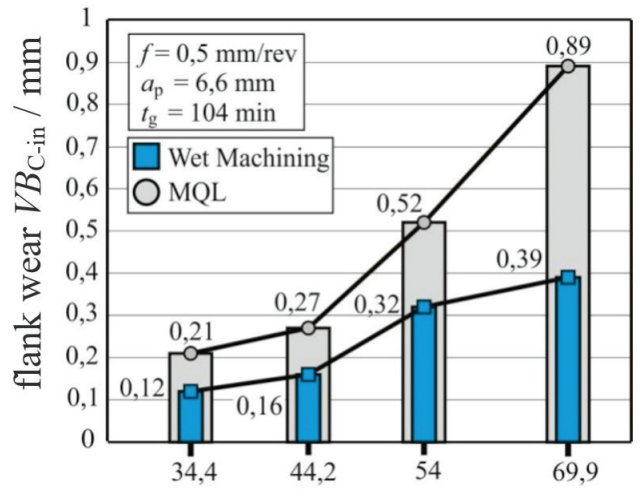

cutting speed $v_{\mathrm{c}} / \mathrm{m} / \mathrm{min}$

Figure 5 Comparison of the maximal $V B_{\text {C-in }}$ wear land width vs. cutting speed after 104 minutes of hobbing for both WM and MQL methods

\subsection{The Relationship between the Tool Life and the Cutting Speed}

As it is known, from among all the factors affecting the tool life $T$ cutting speed $v_{\mathrm{c}}$ is the most important one [12] Because the cutting speed can be varied over a wide range, the tool life can be substantially changed. The mathematic form of this relationship was given by F. W. Taylor as the formula which in logarithmic scales is as follows, e.g. [13]:

$\log T=\log C_{T}-k \cdot \log v_{\mathrm{c}}$

where: $C_{T}$ - the constant which takes into account the impact of the factors not included in the formula, and dependent mainly on the workmaterial; $k$ - the exponent determined experimentally, depending mainly on the tool material.

In Fig. 6, the relationship between the hob tool life $T$ and the cutting speed $v_{\mathrm{c}}$ is presented. In the logarithmic coordinate system, this relationship is linear. The diagram was drawn up on the basis of the results obtained for four cutting speeds with the application of the WM and for the MQL methods pf fluid supply. Other cutting parameters were constant. The criterion of the $V B_{\mathrm{C} \text {-in }}$ wear was assumed at a level of $0,3 \mathrm{~mm}$.

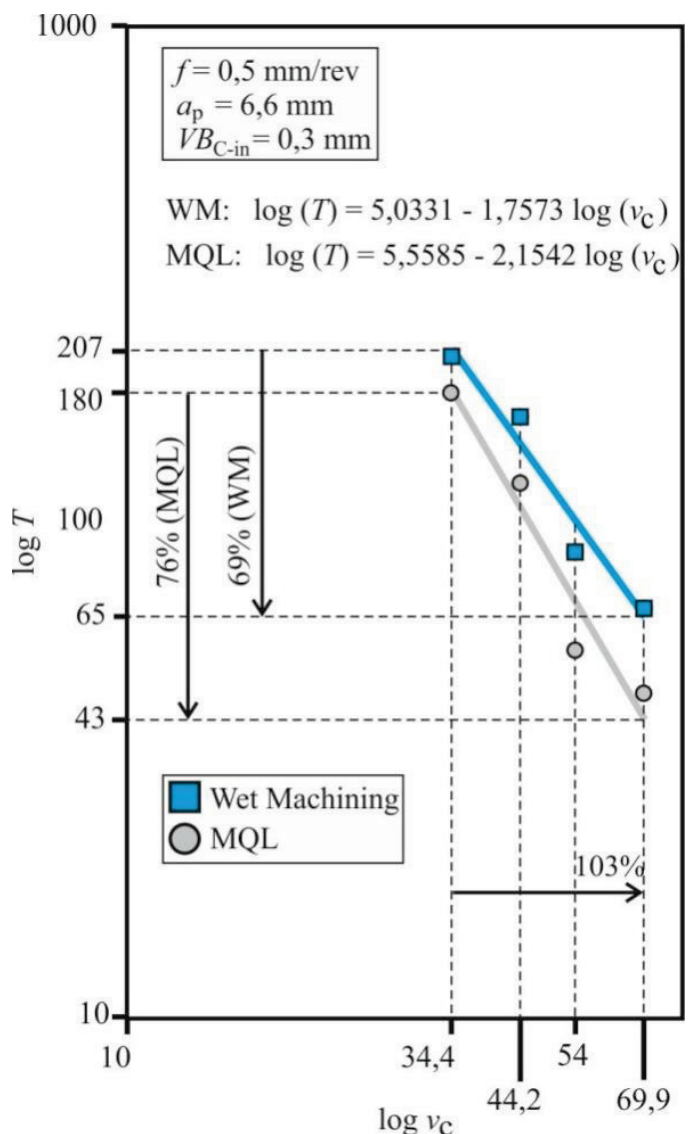

Figure 6 Cutting speed vs. tool life on a log-log scale for two different methods of cutting fluid supply

It is known that the higher value of the $k$ exponent means the lower wear resistance of the tool edge to the effects of high temperatures. Comparing the $k$ coefficients in the two equations shown in Fig. 6, it can be seen that for the MQL method this coefficient amounts to 2,1542, whereas for $\mathrm{WM}$ it is lower and equals 1,7573 . Because in 
both cases hobbing cutters made of the same high-speed steel were used, it can be supposed that the shorter hob tool life when applying the MQL method is obviously the result of the higher temperature in the cutting zone.

It appears from Fig. 6 that for the MQL method an increase in the cutting speed of $103 \%$ causes a decrease in hob tool life by $76 \%$. The same increase of the cutting speed for wet cutting (WM), causes a decrease in the hob tool life of $69 \%$. Therefore it can be concluded that at the hobbing with the use of the tools made of high-speed steel with the MQL method applied, there is a higher sensitivity to machine cutting changes when compared with wet machining.

\section{CONCLUSION}

Based on the results presented above, it can be stated that the supply of cutting fluid in a minimum quantity lubrication ensures, within a certain cutting speeds range, a sufficient lubrication in the machining zone during the entire tool life-time of the hob. Because of that the MQL method can be an alternative method of fluid supply in gear hobbing for the wet machining (WM), especially when dry cutting cannot be applied successfully, and wet machining should be eliminated.

For both methods of cutting fluid supply (MQL and WM) an increase in cutting speed brings on an increase in the $V B_{\mathrm{C} \text {-in }}$ wear rate, whereas for the same $v_{\mathrm{c}}$ values the $V B_{\mathrm{C}-\text { in }}$ lower wear rates occurred for WM. For a cutting speed up to $v_{\mathrm{c}}=54 \mathrm{~m} / \mathrm{min}$, both the inclinations of the wear curves and the $V B_{\mathrm{C} \text {-in }}$ wear rates show that the lubrication in the cutting zone for the MQL method is proper, despite the slightly higher cutting temperatures. For high cutting speeds $\left(v_{\mathrm{c}}=69,9 \mathrm{~m} / \mathrm{min}\right)$ the MQL method does not provide conditions comparable with the WM mode. The wear rate substantially increases indicating a lack of sufficient lubrication and cooling in the cutting zone.

For both methods of cutting fluid supply investigated, the individual cutting edges of the hobbing cutter undergo uneven wear, with different intensity. But the maximum flank wearland width $V B_{\mathrm{C} \text {-in-max }}$ occurs always on one hob's tooth.

\section{REFERENCES}

[1] Sharma, V. S., Singh, G., \& Sørby K. (2015). A review on minimum quantity lubrication for machining processes. Materials and Manufacturing Processes, 30(8), 935-953. https://doi.org/10.1080/10426914.2014.994759

[2] Umbrello, D. \& Rotella, G. (2018). Fatigue life of machined Ti6A14V alloy under different cooling conditions. CIRP Annals - Manufacturing Technology, 67, 99-102. https://doi.org/10.1016/j.cirp.2018.03.017

[3] Benedicto, E., Carou, D., \& Rubio, E. M. (2017). Technical, economic and environmental review of the lubrication/cooling systems used in machining processes. Procedia Engineering, 184, 99-116. https://doi.org/10.1016/j.proeng.2017.04.075

[4] Gupta, K., Laubscher, R. F., Davim, J. P., \& Jain, N. K. (2016). Recent developments in sustainable manufacturing of gears: a review. Journal of Cleaner Production, 112, 3320-3330. https://doi.org/10.1016/j.jclepro.2015.09.133

[5] Matsuoka, H., Ryu, T., Nakae, T., Shutou, S., \& Kodera, T. (2013). Fundamental research on hobbing with minimal quantity lubrication of cutting oil - Comparison of cutting performance with dry cutting. Advances in Materials Science and Applications, 2(3), 88-100.

https://doi.org/10.5963/AMSA0203001

[6] Matsuoka, H., Ryu, T., Nakae, T., Shutou, S., \& Kodera, T. (2013). Fundamental research on hobbing with minimal quantity lubrication of cutting oil - Influence of hardness of work materials under several cutting conditions. Advances in Materials Science and Applications, 2(4), 154-167. https://doi.org/10.5963/AMSA0204004

[7] Bouzakis, K.-D., Lili, E., Michailidis, N., \& Friderikos, O. (2008). Manufacturing of cylindrical gears by generating cutting processes: A critical synthesis of analysis methods. CIRP Annals - Manufacturing Technology, 57, 676-696. https://doi.org/10.1016/j.cirp.2008.09.001

[8] Stachurski, W., Midera, S., \& Kruszyński, B. (2016). Mathematical model describing the course of the process of wear of a hob cutter for various methods of cutting fluid supply. Eksploatacja i Niezawodnosc - Maintenance and Reliability, 18(1), 123-127. https://doi.org/10.17531/ein.2016.1.16

[9] Stachurski, W. (2012). Application of minimal quantity lubrication in gear hobbing. Mechanics and Mechanical Engineering, 16(2), 133-140.

[10] Stachurski, Z. \& Słupik, H. (1997). Hobbing as finishing machining of the hard teeth. Journal of Materials Processing Technology, 64, 353-358. https://doi.org/10.1016/S0924-0136(96)02586-1

[11] Azizpour Jalali, M. \& Majd Mohammadi, H. (2010). Wear mechanisms in high speed steel gear cutting tools. World Academy of Science, Engineering and Technology, 4, 739741.

[12] Stephenson, D. A. \& Agapiou, J.S. (2006). Metal Cutting Theory and Practice. Boca Raton: CRC Press.

[13] Grzesik, W. (2016). Advanced Machining Processes of Metallic Materials: Theory, Modelling and Applications, Second Editions. Amsterdam: Elsevier Science. https://doi.org/10.1016/B978-0-444-63711-6.00015-6

\section{Contact information:}

Wojciech STACHURSKI, PhD Eng

(Corresponding author)

Institute of Machine Tools and Production Engineering

Lodz University of Technology,

1/15 Stefanowskiego Street, 90-924 Lodz, Poland

E-mail: wojciech.stachurski@p.lodz.pl

Bogdan KRUSZYŃSKI, Prof. DSc. PhD Eng.

Institute of Machine Tools and Production Engineering

Lodz University of Technology,

1/15 Stefanowskiego Street, 90-924 Lodz, Poland

E-mail: bogdan.kruszynski@p.lodz.pl 